\title{
PERENCANAAN DAN PENGEMBANGAN SISTEM INFORMASI RUMAH SAKIT BATARA GURU BELOPA
}

\author{
MARIUS LIMPO \\ Staf Pengajar pada Program Studi Teknik Sipil, Fakultas Teknik, Universitas Kristen Indonesia \\ Toraja, E-Mail: mariuslimpo@gmail.com
}

\begin{abstract}
ABSTRAK
Penelitian ini bertujuan merancang sistem informasi rumah sakit menggunakan Yii Framework dan Mysql Sebagai media untuk menyimpan data sistem rumah sakit serta Netbean sebagai editor untuk pembuatan sistem rumah sakit tersebut.

Penelitian ini juga digunakan sebagai objek penelitian dalam mengatasi dan menyelesaikan masalah yang dihadapi oleh rumah sakit Batara Guru Belopa. Perancangan data dari sistem rumah sakit ini dilakukan pengambilan data pada rumah sakit Batara Guru Belopa, agar data dari setiap bagian dalam rumah sakit Batara Guru Belopa tidak mengalami kesalahan.

Pemanfaatan data pada sistem rumah sakit ini adalah agar setiap bagian rumah sakit Batara Guru Belopa saling terhubung, dan setiap bagian saling mengetahui a dirumah sakit Batara Guru Belopa.

Kata Kunci: Rumah Sakit, Sistem Aplikasi.

BAB I

\section{PENDAHULUAN}

\section{A. Latar Belakang}

Sejarah perkembangan komputer tidak terlepas dari sejarah yang menggambarkan usaha manusia yang selalu dihadapkan pada masalah-masalah perhitungan baik untuk usaha bisnis maupun untuk perkembangan ilmu, sehingga manusia selalu berusaha menciptakan peralatan baru dalam meringankan bebannya.

Akibat perkembangan teknologi komputer yang sangat pesat teknologi tersebut saling terkait, perbedaan-perbedaan yang ada dalam hal pengumpulan, pengiriman, penyimpanan, pengolahan informasi dapat teratasi dan memberikan efek yang tidak sedikit bagi perkembangan komputer sehingga baik dalam bentuk maupun perkembangannya mengalami perubahan yang drastis. Setiap perubahan melahirkan komputer generasi baru. Namun sejalan dengan perkembangan teknologi
\end{abstract}


komputer yang sangat pesat akhirnya menuju ke perancangan sistem layanan informasi, yaitu kumpulan dari beberapa informasi yang digabung menjadi satu untuk mencapai sesuatu aspek yang dinginkan. penelitian ini bermaksud untuk merancang suatu sistem informasi.

Dalam pengolahan sistem komputerisasi, pengolahan data sistem informasi dan supaya dalam pengolahan data ketersediaan data informasi dalam sistem dapat menjadi lebih efektif. Sehingga mengakibatkan pemesanan menjadi tidak efektif dan menjadi terganggu. Aplikasi pemrograman PHP (Personal Home Page) dan Database mySQLdapat digunakan untuk mengatasi masalah tersebut.

Menggunakan dasar pemrograman yang biasa tanpa menggunakan framework sangat sulit untuk dilakukan karena para pembuat sistem akan kesulitan membuat prosedu/fungsi yang dibutuhkan. Menggunakan framework lebih mudah untuk melakukan koordinasi dalam pembuatan sistem informasi oleh sebuah tim kerja (sistem analis dan programmer) terkadang menjadi kendala sehingga tidak akan tercapai pembuatan sistem informasi yang baik. Berdasarkan uraian pada latar belakang di atas, maka penulis tertarik untuk mengambil judul:
'PERENCANAAN

DAN

PENGEMBANGAN SISTEM RUMAH

SAKIT PADA RUMAH SAKIT

BATARA GURU BELOPA"

\section{B. Rumusan Masalah}

1. Bagaimana melakukan perencanaan sebuah sistem informasi yang didalamnya yang dapat diakses oleh semua perangkat termasuk blackberry, iphone dan android.

2. Bagaimana membuat website menarik dan interaktif sehingga para pengguna dapat mengecek seluruh aktifitasnya termasuk pembayaran.

\section{Tujuan Penelitian}

1. Untuk melakukan perencanaan sebuah sistem informasi yang didalamnya yang dapat diakses oleh semua perangkat termasuk blackberry, iphone dan android.

2. Untuk membuat website menarik dan interaktif sehingga administrator dapat mengecek seluruh aktifitasnya termasuk meregistrasi para pasien yang akan dirawat di Rumah Sakit Batara Guru Belopa..

\section{Manfaat Penelitian}

1. Membantu para pekerja dan pimpinan Rumah Sakit Batara Guru Belopa agar 
dapat melaksanakan tugasnya dengan mudah.

2. Memberikan kemudahan dalam pembuatan sebuah sistem informasi yang terstruktur dan terencana.

\section{E. Batasan Masalah}

Ruang lingkup pembahasan penelitian ini dibatasi pada:

1. Perencanaan menggunakan Yii Framework.

2. Implementasi programming terdiri dari 3 hal yaitu subdomain admin, root, dan subdomain client.

\section{BAB II}

\section{TINJAUAN PUSTAKA}

\section{A. Sistem Informasi}

Sistem informasi adalah gabungan dari teknologi informasi dan aktivitas orang yang menggunakan teknologi itu untuk mendukung operasi dan manajemen. Dalam arti yang sangat luas, istilah sistem informasi yang sering digunakan merujuk pada interaksi antara orang, proses algoritmik, data, dan teknologi. Dalam pengertian ini, istilah yang digunakan untuk merujuk tidak hanya pada penggunaan organisasi teknologi informasi dan komunikasi (TIK), tetapi juga untuk cara dimana orang bertinteraksi dengan teknologi ini dalam mendukung proses bisnis.

Sistem informasi dalam dunia bisnis dan pemerintahan mempunyai tiga tujuan utama yaitu :

1. Menyediakan informasi guna mendukung pengambilan keputusan.

2. Menyajikan informasi guna mendukung operasi harian.

3. Menyediakan informasi yang berkenan dengan pengurusan.

Dua tujuan utama menyangkut kepentingan internal dan eksternal, sedangkan yang ketiga hanya untuk internal. Hampir semua informasi yang dibutuhkan oleh dua tujuan terakhir merupakan data transaksi yang telah diolah, sementara yang pertama saja hanya sebagian data yang diolah.

\section{B. Yii Framework}

Yii adalah framework (kerangka kerja) PHP berbasis-komponen, berkinerja tinggi untuk pengembangan aplikasi Web berskala-besar. Yii menyediakan reusability maksimum dalam pemrograman $\mathrm{Web}$

Yii Framewwork pertama kali dikembangkan oleh seorang master bernama Qiang Xue pada Januari 2008 dan pada Desember 2008 Yii 1.0 dirilis untuk publik. Dan sunggu menakjubkan, baru berselang beberapa tahun Yii sekarang sudah menjadi PHP framework yang diminati banyak.Yii 
sendiri tentunya tidak kalah bagus dengan PHP Framework yang lainnya, hal tersebut dapat dilihat dari segudang fitur yang dimiliki oleh Yii sendiri. Fitur - fitur dari Yii Framework antara lain :

- Menggunakan Pola MVC

- Database Access Objects (DAO), Query Builder, Active Record, DB Migration

- Form input and validation

- AJAX(Asynchronous JavaScript and XML)-enabled widgets

- Authentication and authorization

- Automatic code generation

- Extension library

\section{PHP (Page Hypertext}

Preprocessor)

\section{PHP (Page Hypertext Preprocessor)}

adalah bahasa scripting yang bersifat Open Source yang banyak dipergunakan khususnya untuk pengembangan web dan dapat diimplementasikan ke dalam HTML.

PHP pada umumnya terfokus untuk server side scripting (diperlukan suatu web server untuk menjalankannya), sehingga anda dapat melakukan apapun yang dapat dilakukan oleh program CGI lainnya. Seperti mengumpulkan data, membuat halaman yang bersifat dinamis, atau mengirim dan menerima cookies. Tetapi PHP dapat melakukan lebih banyak hal lainnya lagi.
Jika anda menggunakan web server yang diinstalasi secara terpisah maka anda harus terlebih dahulu melakukan konfigurasi pada web server dan file library PHP anda sebelum anda dapat menjalankan file PHP anda pada web server yang akan anda gunakan.

Jika anda menggunakan ZendServer, sebagai aplikasi anda dan mengikuti langkah instalasi yang telah diberikan diatas, maka anda dapat menggunakan Apache yang telah diikutsertakan dalam aplikasi tersebut dan anda tidak perlu melakukan konfigurasi apa pun untuk menjalankan file PHP anda dan anda juga dapat mencoba menjalankan contoh file PHP diatas sesuai dengan langkah-langkah diberikan dibawah. Adapun langkah yang diperlukan untuk menjalankan file PHP menggunakan Apache yang terdapat dalam aplikasi phptriad ini, ialah sebagai berikut:

1. Menyimpan file PHP anda dengan nama_file.php pada folder c:lappservlhtdocldata (ini merupakan lokasi default untuk menyimpan file-file web anda).

2. Kemudian setelah melakukan langkah diatas, maka anda dapat membuka web browser anda. Kemudian mengetikkan http://localhost/nama_file.php pada 
kolom URL anda. Tekan enter untuk menampilkan halaman web anda

\section{MySQL}

MySQL adalah perangkat lunak sistem manajemen basis data atau yang biasa disebut DBMS (database management sistem). My soql adalah perangkat lunak yang gratis yang berada dibawah lisensi GPL (General Public License).

MySQL adalah sebuah implementasi dari sistem manajemen basisdata relasional (RDBMS) yang didistribusikan secara gratis dibawah lisensi GPL (General Public License). MySQL sebenarnya merupakan turunan salah satu konsep utama dalam basisdata yang telah ada sebelumnya (structured Query Language) atau SQL.

SQL adalah sebuah konsep pengoperasian basisdata, terutama untuk pemilihan atau seleksi dan pemasukan data, yang memungkinkan pengoperasian data dikerjakan dengan mudah secara otomatis. Kehandalan suatu sistem basisdata (DBMS) dapat diketahui dari cara kerja pengoptimasi-nya dalam melakukan proses perintah-perintah SQL yang dibuat oleh pengguna maupun program-program aplikasi yang memanfaatkannya. Sebagai peladen basis data, MySQL mendukung operasi basisdata transaksional maupun operasi basisdata non-transaksional.
Beberapa keistimewaan dari MySQL :

1. Portabilitas. MySQL dapat berjalan stabil pada berbagai sistem operasi seperti Windows, Linux, FreeBSD, Mac Os X Server, Solaris, Amiga, dan masih banyak lagi.

2. Perangkat lunak sumber terbuka. MySQL didistribusikan sebagai perangkat lunak sumber terbuka, dibawah lisensi GPL sehingga dapat digunakan secara gratis.

3. Multi-user. MySQL dapat digunakan oleh beberapa pengguna dalam waktu yang bersamaan tanpa mengalami masalah atau konflik.

4. Performance tuning', MySQL memiliki kecepatan yang menakjubkan dalam menangani query sederhana, dengan kata lain dapat memproses lebih banyak SQL per satuan waktu.

5. Ragam tipe data. MySQL memiliki ragam tipe data yang sangat kaya, seperti signed / unsigned integer, float, double, char, text, date, timestamp, dan lain-lain.

6. Perintah dan Fungsi. MySQL memiliki operator dan fungsi secara penuh yang mendukung perintah Select dan Where dalam perintah (query).

7. Keamanan. MySQL memiliki beberapa lapisan keamanan seperti level 
subnetmask, nama host, dan izin akses user dengan sistem perizinan yang mendetail serta sandi terenkripsi.

8. Skalabilitas dan Pembatasan. MySQL mampu menangani basis data dalam skala besar, dengan jumlah rekaman (records) lebih dari 50 juta dan 60 ribu tabel serta 5 milyar baris. Selain itu batas indeks yang dapat ditampung mencapai 32 indeks pada tiap tabelnya.

9. Konektivitas. MySQL dapat melakukan koneksi dengan klien menggunakan protokol TCP/IP, Unix soket (UNIX), atau Named Pipes (NT).

10. Lokalisasi. MySQL dapat mendeteksi pesan kesalahan pada klien dengan menggunakan lebih dari dua puluh bahasa. Meski pun demikian, bahasa Indonesia belum termasuk di dalamnya.

11. Antar Muka. MySQL memiliki antar muka (interface) terhadap berbagai aplikasi dan bahasa pemrograman dengan menggunakan fungsi API (Application Programming Interface).

12. Klien dan Peralatan. MySQL dilengkapi dengan berbagai peralatan (tool)yang dapat digunakan untuk administrasi basis data, dan pada setiap peralatan yang ada disertakan petunjuk online.

13. Struktur tabel. MySQL memiliki struktur tabel yang lebih fleksibel dalam menangani ALTER TABLE, dibandingkan basis data lainnya semacam PostgreSQL ataupun Oracle.

Beberapa fungsi dari MySQL :

1. mysq1_connect : Digunakan untuk membuka hubungan (koneksi) dengan MySQL server.

2. mysql_pconnect : Membuka hubungan (koneksi) permanen/tetap dengan MySQL server.

3. mysql_create_db : Membuat sebuah database baru pada server database MySQL.

\section{E. NETBEANS}

Netbeans merupakan sebuah aplikasi Integrated Development Environment (IDE) yang berbasiskan Java dari Sun Microsystems yang berjalan di atas swing. Swing merupakan sebuah teknologi Java untuk pengembangan aplikasi desktop yang dapat berjalan pada berbagai macam platform seperti windows, linux, Mac OS X dan Solaris. Sebuah IDE merupakan lingkup pemrograman yang di integrasikan ke dalam suatu aplikasi perangkat lunak yang menyediakan Graphic User Interface (GUI), suatu kode editor atau text, suatu compiler dan suatu debugger.

Netbeans juga digunakan untuk menulis, mengcompile, mencari kesalahan dan menyebarkan program netbeans yang 
ditulis dalam bahasa pemrograman java namun selain itu dapat juga mendukung bahasa pemrograman lainnya dan program ini pun bebas untuk digunakan dan untuk membuat professional desktop, enterprise, web, and mobile applications dengan Java language, $\mathrm{C} / \mathrm{C}++$, dan bahkan dynamic languages seperti PHP, JavaScript, Groovy, dan Ruby.

NetBeans merupakan sebuah proyek kode terbuka yang sukses dengan pengguna yang sangat luas, komunitas yang terus tumbuh, dan memiliki hampir 100 mitra (dan terus bertambah!). Sun Microsystems mendirikan proyek kode terbuka NetBeans pada bulan Juni 2000 dan terus menjadi sponsor utama. Dan saat ini pun netbeans memiliki 2 produk yaitu Platform Netbeans dan Netbeans IDE. Platform Netbeans merupakan framework yang dapat digunakan kembali (reusable) untuk menyederhanakan pengembangan aplikasi desktop dan Platform NetBeans juga menawarkan layanan-layanan yang umum bagi aplikasi desktop, mengijinkan pengembang untuk fokus ke logika yang spesifik terhadap aplikasi. Fitur-fitur yang terdapat dalam NetBeans antara lain :

1. Smart Code Completion: untuk mengusulkan nama variabel dari suatu tipe, melengkapi keyword dan mengusulkan tipe parameter dari sebuah method.

2. Bookmarking: fitur yang digunakan untuk menandai baris yang suatu saat hendak kita modifikasi.

3. Go to commands: fitur yang digunakan untuk jump ke deklarasi variabel, source code atau file yang ada pada project yang sama.

4. Code generator: jika kita menggunakan fitur ini kita dapat meng-generate constructor, setter and getter method dan yang lainnya.

5. Error stripe: fitur yang akan menandai baris yang eror dengan memberi highlight merah.

Dengan menggunakan NetBeans sebagai code editor programmer dapat membuat sistem informasi pada Rumah Sakit Batara Belopa.

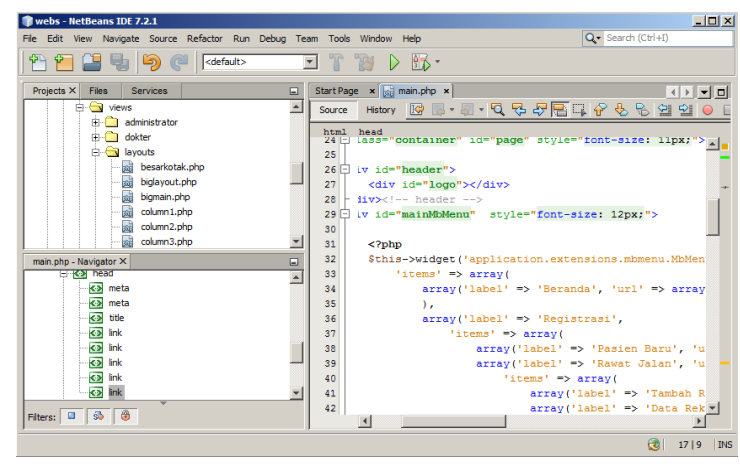

Gambar 2.1 NetBeans sebagai code editor. 


\section{BAB III}

\section{METODE PENELITIAN}

\section{A. Lokasi dan Waktu Penelitian}

Penelitian ini telah dilakukan di Kota Belopa yakni tepatnya di rumah sakit Batara Guru Belopa yang diimplementasikan dalam pengembangan sistem informasi. Diberikan kasus dalam mengembangkan aplikasi yaitu SIMRS(Sistem Informasi Manajemen Rumah Sakit).

\section{B. Sumber Data}

Dalam penelitian ini ada beberapa jenis data yang telah diambil sebagai bahan antara lain:

1. Data awal dari persyaratan sistem sebagai bahan pembuatan perancangan.

2. Data hasil perancangan dari pihak rumah skait untuk pengembangan perangkat lunak.

3. Hasil dari pembuatan program.

\section{A. Tahap Penelitian}

2. Studi Literatur, yaitu dengan melakukan studi dari buku-buku pustaka yang berkaitan dengan masalah yang dibahas, juga melalui artikel-artikel dari internet.

3. Metode Pengambilan Data yaitu:

Observasi langsung dengan subyek berupa pengambilan data.

4. Langkah-langkah dalam tahap penelitian: a. Analis Sistem mendefinisikan fiturfitur sistem, membuat perencanaannya dan melakukan diskusi dengan para programmer tentang sistem yang akan dibuat.

b. Para programmer mempelajari Perencanaan Sistem yang dibuat oleh analis sistem dan membuatnya klasklas dari tiap fitur yang dibutuhkan.

c. Hasil yang telah baik ataupun belum memuaskan diperiksa dan diubah jika perlu.

d. Klas-klas diintegrasikan kedalam program utama dan lakukan testing sebelum dan sesudah diintegrasikan.

\section{B. Strategi Pengembangan Sistem}

Dalam penelitian ini menggunakan standard coding, pair programming dan refactoring sehingga melibatkan beberapa orang yaitu:

Programmer : 4 Orang.

Analis sistem : 1 Orang.

\section{Gambaran Umum Sistem}

\section{Perangkat Keras Sistem}

Perangkat keras yang digunakan dalam proses pembuatan sistem ini adalah:

a. Komputer/desktop sebanyak 3 Buah : Proc. Intel Dual Core

b. Laptop sebanyak 1 Buah : Proc.Intel Dual Core 
c. Switch Hub sebanyak 1 buah

: Access Point

\section{Perangkat Lunak Sistem}

a. Windows 7 sebagai sistem operasinya.

b. Yii Framework, digunakan dalam pengembangan sistem informasi.

c. Apache 2.2 sebagi webserver.

d. Macromedia Dreamweaver dan Eclipse PDT serta Netbeans, digunakan untuk membuat file-file php.

\section{Desain Sistem Informasi Rumah Sakit}

Secara skematik, desain Sistem Informasi rumah sakit digambarkan sebagai berikut:

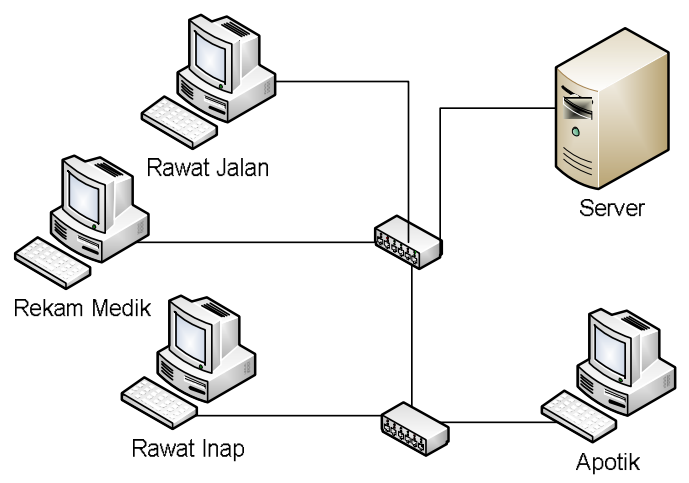

Gambar 3.1 Skema desain Sistem Informasi

\section{Rumah Sakit}

Sistem informasi Rumah Sakit adalah sistem yang mengakomondasi seluruh informasi yang berada dalam rumah sakit, sehingga pihak manajemen tidak membutuhkan lagi penulisan secara kertas. Pencarian informasi pasien dapat langsung diketahui melalui sistem yang telah terpasang dalam rumah sakit tersebut. Membuat laporan sangat mudah.

Persyaratan Sistem (System Requirement)

Tabel 3.1 Persyaratan Sistem

\begin{tabular}{|c|c|}
\hline No. & Fungsional \\
\hline 1 & 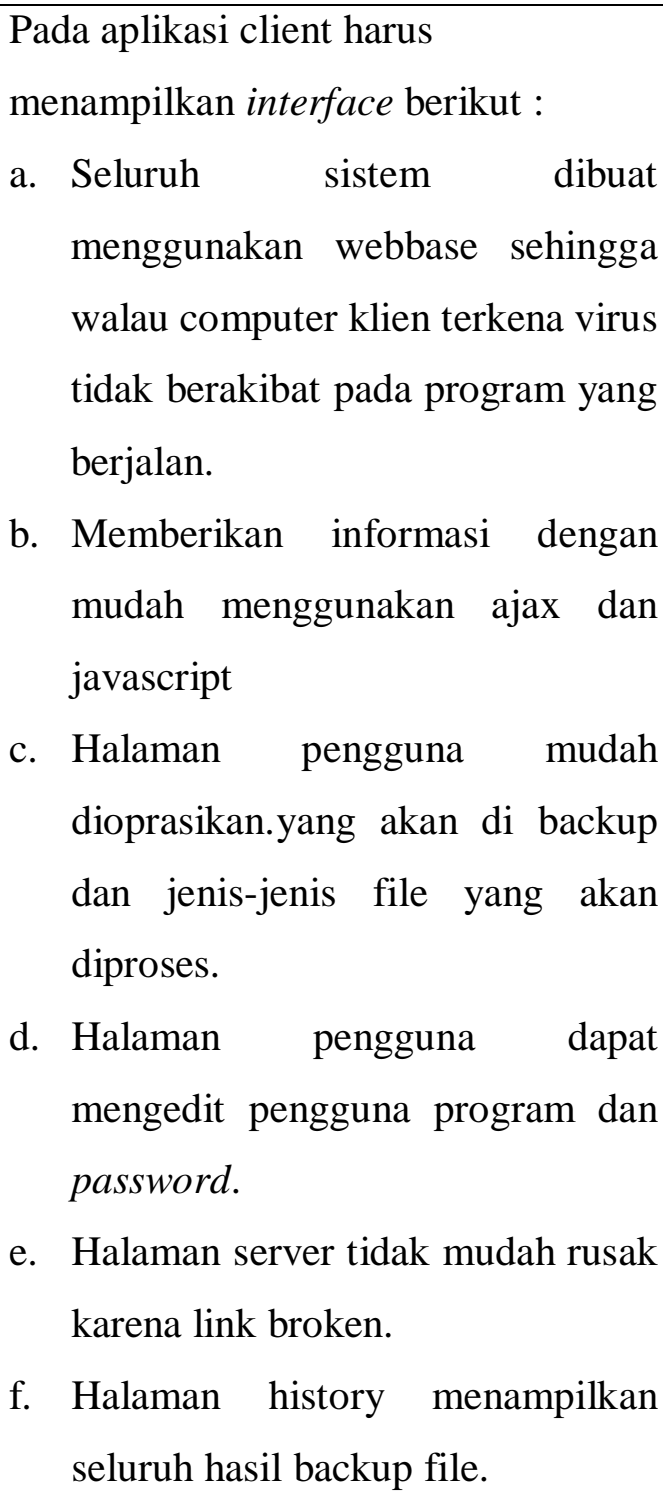 \\
\hline 2 & $\begin{array}{l}\text { Komunikasi antara client dan server: } \\
\text { a. Protokol yang digunakan adalah } \\
\\
\text { HTTP. } \\
\text { b. Pengiriman data dari server } \\
\text { menggunakan } X M L \text { dan } T E X T \text {. }\end{array}$ \\
\hline
\end{tabular}




\begin{tabular}{|c|c|}
\hline 3 & $\begin{array}{l}\text { Fungsi-fungsi dari aplikasi server: } \\
\text { a. Melayani permintaan } C R C 32, \\
\text { download file, upload file dan } \\
\text { informasi file dan direktori. } \\
\text { b. Dapat perjalan pada apache dan } \\
\text { linux. } \\
\text { c. Pengiriman data menggunakan } \\
\text { XML dan TEXT. } \\
\text { d. Dapat melayani sangat banyak } \\
\text { client. } \\
\text { e. Seluruh data disimpan dalam } \\
\text { database. } \\
\text { f. Database menggunakan } M y S Q L . \\
\text { g. Menggunakan nama domain }\end{array}$ \\
\hline & Non Fungsional \\
\hline 1 & $\begin{array}{l}\text { menggunakan mysql } 5.2 \text { untuk } \\
\text { database server. } \\
\text { menggunakan apache } 2 \text { untuk web } \\
\text { server. } \\
\text { program dibuat menggunakan Yii } \\
\text { Framework. } \\
\text { program server dibuat menggunakan } \\
\text { php. }\end{array}$ \\
\hline
\end{tabular}

BAB IV

\section{HASIL DAN PEMBAHASAN}

i. Disain Sistem Informasi

1. Gambaran Umum Sistem

Informasi Rumah Sakit
Sistem informasi rumha sakit adalah sistem yang servernya berjalan dengan menggunakan sistem operasi linux dan client nya menggunakan windows, baik windows 7 ataupun windows 8, sistem ini berjalan secara webbase atau boleh dikatakan bahwa tugas-tugas backup dilakukan secara otomatis. Sistem tersebut membandingkan CRC32 dari file yang pada folder yang telah ditentukan dengan yang berada pada server sehingga apabila CRC32 dari kedua file tersebut berbeda maka backup akan dilakukan dengan penggunakan metode POST via HTTP. Secara garis besarnya dapat dilihat pada gambar collaborative process berikut ini.

Dengan adanya pemeliharaan secara rutin, maka pengguna tidak akan kuatir apabila datanya hilang pada computer klien karena dapat langsung mengembalikan file tersebut. Kecepatan backup ataupun restore file tergantung pada kecepatan koneksi. Client-Server adalah arsitektur jaringan yang memisahkan client (biasanya aplikasi yang menggunakan $G U I$ ) dengan server. Masingmasing client dapat meminta data atau informasi dari server. Pengembangan sistem client-server dapat digambarkan sebagai berikut: 


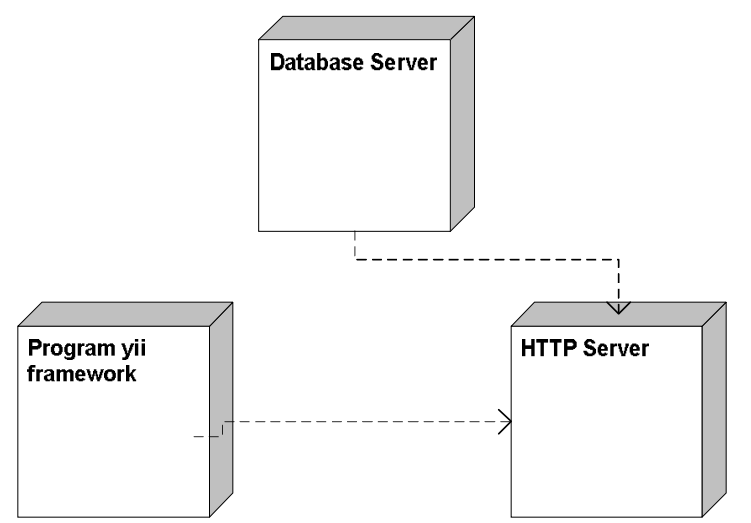

Gambar 4.1 Diagram client-server deployment

Gambar tadi menunjukkan bahwa HTTP (Hypertext Transfer Protocol) merupakan protokol yang dipergunakan untuk mentransfer dokumen dalam World Wide Web $(W W W)$. Protokol ini adalah protokol ringan, tidak berstatus dan generik yang dapat dipergunakan untuk berbagai macam tipe dokumen. HTTP juga merupakan sebuah protokol meminta atau menjawab hubungan antara client dan server.

Gambar berikut adalah diagram use case dari Sistem Informasi Rumah sakit.

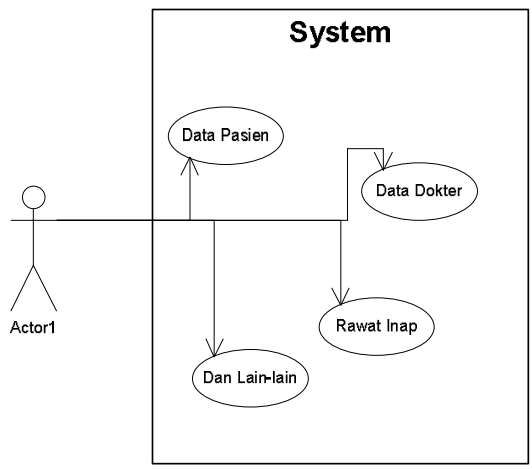

Gambar 4.2 Use Case Diagram
Gambar sebelumnya menunjukkan bahwa pengguna dapat memasukkan mengakses seluruh data yang ada dalam sistem tersebut. Dapat dilihat bahwa datadata yang bersangkutan dengan rumah sakit bisa diakses.

\section{Database sistem informasi rumah} sakit

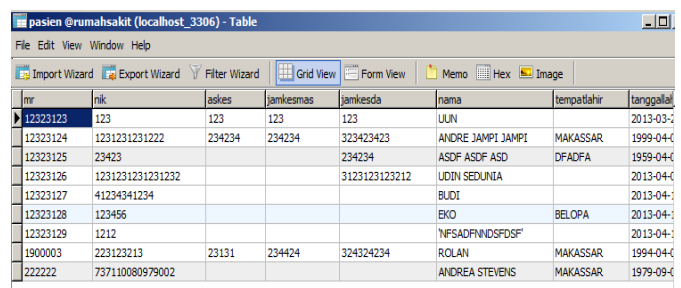

tabel 4.3 tabel pasien

dalam tabel ini tersimpan data seluruh pasien Rumah Sakit Umur Batara Guru Belopa. Mulai dari informasi KTP sampai dengan keluarga terdekat.

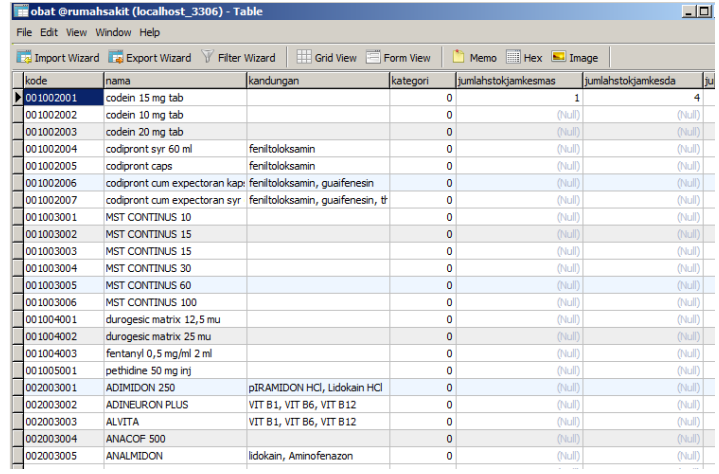

Tabel 4.4 daftar obat

Dalam tabel sebelumnya dapat dilihat data obat yang berada dalam apotik rumah sakit batara guru belopa. 


\begin{tabular}{|c|c|c|c|c|c|c|}
\hline \multicolumn{7}{|c|}{ E tarifrawatinap @rumahsakit (localhost_3306) - Table } \\
\hline \multicolumn{7}{|c|}{ File Edit View Window Help } \\
\hline \multicolumn{4}{|c|}{ EE Import Wizard Export Wizard $\quad \nabla$ Filter Wizard } & \multicolumn{2}{|c|}{ 四 Grid View Form View } & \multirow{2}{*}{$\begin{array}{l}\text { - }{ }^{*} \text { Memo } \\
\left.\right|_{\text {lipgizi }}\end{array}$} \\
\hline id & jenisruangan & jasasarana & jpmedik & jpperawat & jipnonmedik & \\
\hline$D$ & 1 VIP UTAMA & 100000 & 82500 & 37500 & 27000 & 3000 \\
\hline & 2 VIP A & 80000 & 66000 & 30000 & 21600 & 2400 \\
\hline & 3 VIP B & 70800 & 58410 & 26550 & 19116 & 2124 \\
\hline & 4 KELAS I & 60000 & 49500 & 22500 & 16200 & 1800 \\
\hline & 5 KELAS II & 40000 & 33000 & 15000 & 10800 & 1200 \\
\hline & 6 KELAS III & 30000 & 24750 & 11250 & 8100 & 900 \\
\hline & 7 ICU & 140000 & 105000 & 63000 & 37800 & 4200 \\
\hline & $8 \mathrm{HCU}$ & 60000 & 45000 & 27000 & 16200 & 1800 \\
\hline & 9 INCUBATOR & 40000 & 33000 & 15000 & 10800 & 1200 \\
\hline & 10 ONE DAY CARE & 28000 & 23100 & 10500 & 7560 & 840 \\
\hline
\end{tabular}

tabel 4.5 daftar kelas

daftar kelas dan harga yang telah ditetapkan oleh pemerintah, dalam daftar tersebut tercantum berbagai kebutuhan sesuai dengan kelasnya.

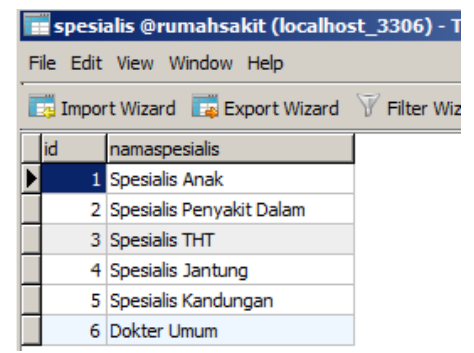

Tabel 4.6 daftar dokter spesialis Dalam tabel diatas tercantum informasi yang jelas tentang berbagai spesialisasi.

\section{B. Pengujian Hasil Pengembangan}

\section{Sistem Informasi Rumah sakit batara}

\section{guru belopa}

Gambar berikut menunjukkan screen shoot program yang telah dikembangkan, dari halaman utama sampai seterusnya.

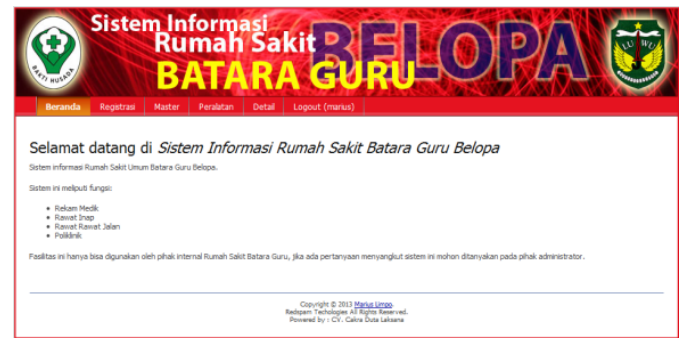

Gambar 4.7 Form halaman utama
Ketika Program dijalankan maka tampilan pertama yang keluar seperti pada gambar sebelumnya.

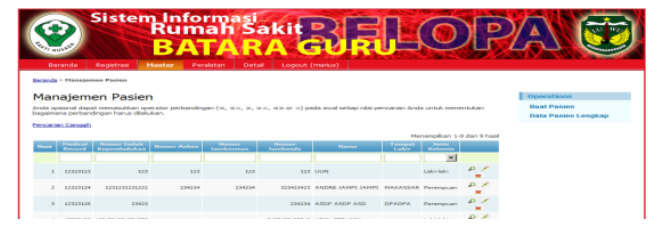

Gambar 4.8 Form data pasien

para admin dapat melihat data pasien dengan membuka halaman diatas.

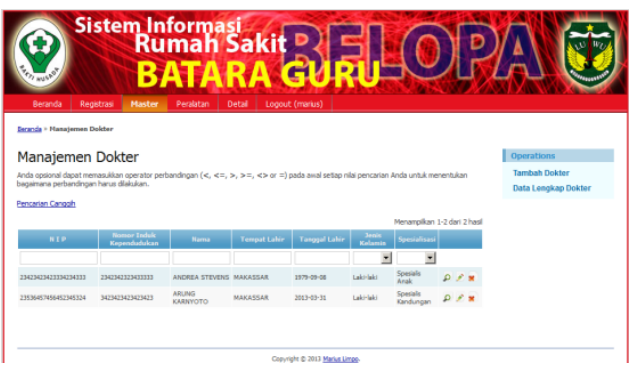

Gambar 4.9 Data Dokter

Untuk melihat data dokter kita dapat membuka halaman seperti yang terlihat pada gambar sebelumnya.

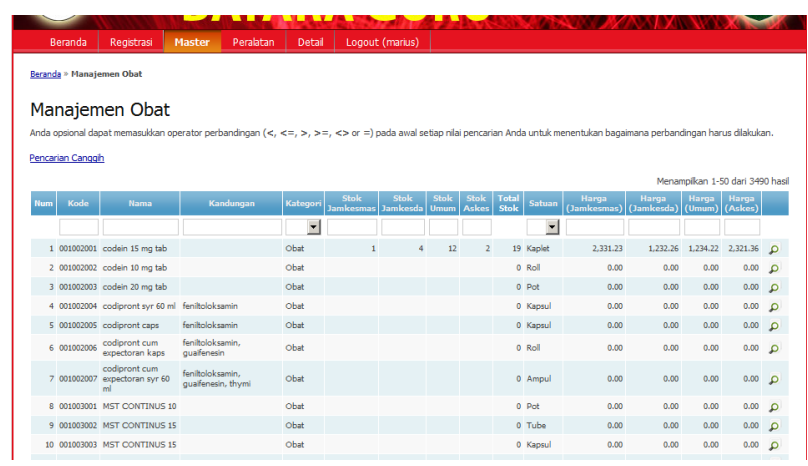

Gambar 4.10 manajemen obat 
input data obat dapat dilakukan dengan menggunakan fasilitas seperti diatas.

\section{BAB V \\ PENUTUP}

\section{A. Kesimpulan}

1. Perencanaan sistem informasi Rumah sakit batara guru belopa ternyata dapat menjelaskan proses terbesar hingga yang paling kecil (terperinci/detail), teratur dan berkesinambungan sehingga mudah dimengerti oleh programmer dan analis sistem atau para perekayasa perangkat lunak pada umumnya.

2. Pengembangan sistem informasi Rumah sakit batara guru belopa menggunakan metode extreme programming ternyata listing program yang dihasilkan dapat mudah dimengerti.

\section{B. Saran}

1. Diperlukan pengembangan lanjutan yang lebih kompleks.

2. Diharapkan adanya penelitian menggunakan framework yang lainnya.

3. Diharapkan adanya penelitian lebih lanjut yang dapat menghasilkan $s \quad n$ informasi dengan tingkat ketelitian serta kinerja yang lebih baik.

\section{DAFTAR PUSTAKA}

Al Fatta, Hanif. 2007. Analisis dan Perancangan Sistem Informasi. Yogyakarta: Andi.

Munawar. 2005. Pemodelan Visual dengan UML. Yogyakarta: Graha Ilmu.
Nugroho, Bunafit. 2004. Database Relasional Dengan MySQL. Yogyakarta: Andi.
Peranginangin, Kasiman. 2006. Aplikasi WEB dengan PHP dan MySQL. Yogyakarta : Andi.

Sulistiyani, Sri. 2008. Membuat Aplikasi Database dengan Java dan MySQL. Yogyakarta: Andi.

Kobryn, C. 2008, BPMN Simplified ${ }^{\mathrm{TM}}$ Workshop (online), http://www.ptcorp. com/docs/workshops/PTC-BPMN-

Workshop.pdf (akses terakhir 21

Februari 2008).

Marc, C, 2003, What Is Extreme Programming?, (Online), http://www.code project.com/KB/architecture/XP.aspx (akses terakhir 24 Februari 2009). 
Owen, Martin, 2003, Introduction to the New Business Modeling Standard, (Online),http://www.omg.org/bpmn/D ocuments /6AD5D16960 .BPMN _and_BPM.pdf (akses terakhir 15 April 2009).

Simarmata, Janner, 2009, Rekayasa Perangkat Lunak, Penerbit Andi, Jogyakarta.

Sommerville, Ian. 2000. Software Engineering. $6^{\text {th }}$ Edition. McGraw-Hill Book Co. 